\title{
The Role of Surface Defects in the Adsorption of Methanol on $\mathrm{Fe}_{3} \mathrm{O}_{4}(001)$
}

\author{
Oscar Gamba $^{1} \cdot$ Jan Hulva $^{1} \cdot$ Jiri Pavelec $^{1} \cdot$ Roland Bliem $^{1} \cdot$ Michael Schmid $^{1}$. \\ Ulrike Diebold $^{1} \cdot$ Gareth S. Parkinson $^{1}$
}

Published online: 13 September 2016

(c) The Author(s) 2016. This article is published with open access at Springerlink.com

\begin{abstract}
The adsorption of methanol $\left(\mathrm{CH}_{3} \mathrm{OH}\right)$ at the $\mathrm{Fe}_{3} \mathrm{O}_{4}(001)-(\sqrt{ } 2 \times \sqrt{ } 2) \mathrm{R} 45^{\circ}$ surface was studied using $\mathrm{X}$-ray photoelectron spectroscopy, scanning tunneling microscopy, and temperature-programmed desorption (TPD). $\mathrm{CH}_{3} \mathrm{OH}$ adsorbs exclusively at surface defect sites at room temperature to form hydroxyl groups and methoxy $\left(\mathrm{CH}_{3} \mathrm{O}\right)$ species. Active sites are identified as step edges, iron adatoms, antiphase domain boundaries in the $(\sqrt{ } 2 \times \sqrt{2}) \mathrm{R} 45^{\circ}$ reconstruction, and above $\mathrm{Fe}$ atoms incorporated in the subsurface. In TPD, recombinative desorption is observed around $300 \mathrm{~K}$, and a disproportionation reaction to form methanol and formaldehyde occurs at $470 \mathrm{~K}$.
\end{abstract}

Keywords Oxide surfaces - Surface defects - Methanol · Magnetite $\cdot$ Surface chemistry

\section{Introduction}

Methanol $\left(\mathrm{CH}_{3} \mathrm{OH}\right)$, the simplest alcohol, can be involved in several processes to produce hydrogen (oxidative reforming, decomposition, steam reforming) [1] and has received renewed interest for its importance in fuel-cell technology [2]. Moreover, methanol chemisorption has been termed a "smart chemical probe" [3] to study active sites on metal-oxide catalysts because adsorption allows to quantify the density of active sites, while the product distribution observed upon desorption is thought to reflect the nature of the active sites.

\footnotetext{
Gareth S. Parkinson

parkinson@iap.tuwien.ac.at

Institute of Applied Physics, TU Wien, Vienna, Austria
}

Studies of methanol adsorption on well-characterized metal-oxide surfaces have sought to correlate the atomicscale structure with chemical reactivity [3-13]. Methanol does not typically chemisorb at truncated-bulk oxide surfaces, and some degree of additional coordinative unsaturation is required for dissociative adsorption, for example at step edges $[11,12]$. Oxygen vacancies $\left(\mathrm{V}_{\mathrm{O}} \mathrm{s}\right)$ have been shown to be the major active sites on $\mathrm{TiO}_{2}[7,8]$ and $\mathrm{CeO}_{2}$ $[9,10]$ surfaces, with adsorbed methoxy species $\left(\mathrm{CH}_{3} \mathrm{O}^{-}\right)$ and hydroxyl groups formed at room temperature. Reaction products such as formaldehyde and methane are reported to emerge from this chemistry. However, as noted by Vohs in his recent review of oxygenate adsorption on metal oxides [4], little is known about the reactivity of isolated cation defects.

Iron oxides represent an interesting case in this regard because their bulk defect chemistry is dominated by the cation sublattice, with little evidence that $\mathrm{V}_{\mathrm{O}}$ s form in the bulk, or at the surface. Indeed, a recent study on the $\mathrm{Fe}_{3} \mathrm{O}_{4}(111)$ surface [14] found dissociative adsorption on Fe-terminated regions of the surface, and concluded this to occur via a Brønsted acid-base mechanism requiring undercoordinated cation-anion pairs. Recombination to produce methanol was observed at $330-360 \mathrm{~K}$ in TPD, along with a disproportionation reaction between two adsorbed methoxy species to produce methanol and formaldehyde as follows [14]

$2 \mathrm{CH}_{3} \mathrm{O}_{\text {ads }} \rightarrow \mathrm{CH}_{3} \mathrm{OH}_{\text {gas }}+\mathrm{CH}_{2} \mathrm{O}_{\text {gas }}$

In this paper, we study the adsorption of $\mathrm{CH}_{3} \mathrm{OH}$ on the magnetite $\mathrm{Fe}_{3} \mathrm{O}_{4}(001)$ surface, with an emphasis on the role of isolated cation defects. This surface exhibits a $(\sqrt{ } 2 \times \sqrt{2}) \mathrm{R} 45^{\circ}$ reconstruction over a wide range of oxygen chemical potentials [15] based on a rearrangement of the cations in the second and third surface layers [16]. 
The reconstructed unit cell, indicated by a purple square in Fig. 1a, contains four octahedrally coordinated $\mathrm{Fe}_{\text {oct }}$ atoms (dark blue spheres) and eight oxygen atoms (red spheres) in the surface layer. The second layer contains three tetrahedrally coordinated $\mathrm{Fe}_{\text {tet }}$ atoms (light blue spheres), one of which is an additional interstitial atom labelled $\mathrm{Fe}_{\text {int }}$. Essentially, this atom replaces two $\mathrm{Fe}_{\text {oct }}$ atoms in the third layer resulting in a net removal of one cation per unit cell and a more oxidized surface. According to angle-resolved XPS and abinitio (DFT $+\mathrm{U})$ calculations, all $\mathrm{Fe}$ atoms in the outermost four layers are $\mathrm{Fe}^{3+}$ [16]. Hereafter, we will refer to this surface structure as the subsurface cation vacancy $(\mathrm{SCV})$ reconstruction.

In prior studies, formic acid and, to some degree, water have been found to dissociate on this surface at room temperature $[17,18]$. Here, using a combination of STM, XPS, and TPD, we demonstrate that methanol adsorption is restricted to surface defects. Specifically, the active sites are determined to be step edges, Fe adatoms, antiphase domain boundaries (APDBs) in the $(\sqrt{ } 2 \times \sqrt{ } 2) \mathrm{R} 45^{\circ}$ reconstruction, and $\mathrm{Fe}$ atoms incorporated in the subsurface. Adsorption at the former two defects is due to the high coordinative unsaturation of the cations at such sites, whereas reactivity at the latter two defects is linked to the presence of $\mathrm{Fe}^{2+}$. Desorption occurs via two channels in TPD; recombination to methanol, and a disproportionation reaction to form methanol and formaldehyde.

\section{Materials and Methods}

The experiments were performed in ultrahigh vacuum (UHV). A natural $\mathrm{Fe}_{3} \mathrm{O}_{4}(001)$ sample (SurfaceNet $\mathrm{GmbH}$ ) was prepared in situ by $1 \mathrm{keV} \mathrm{Ar}^{+}$sputtering at room temperature for 20 min followed by annealing in UHV at $873 \mathrm{~K}$ for $15 \mathrm{~min}$. Once no contamination could be detected by XPS in the $\mathrm{C} 1 s$ region, the sample was annealed in $\mathrm{O}_{2}\left(5 \times 10^{-7} \mathrm{mbar}\right)$ at $873 \mathrm{~K}$ for $15 \mathrm{~min}$, which results in a surface with the SCV reconstruction. To create a surface with an increased defect density, Fe was evaporated from a 2-mm-thick rod $(99.99+\%$, MaTeck $\mathrm{GmbH})$ at room temperature using an Omicron electronbeam evaporator; the deposition rate was calibrated by a quartz crystal microbalance. Methanol was obtained from Sigma Aldrich at a purity of $99.8 \%$ and purified with several freeze-pump-thaw cycles. For the STM experiments methanol vapour was dosed into the background in the chamber through a high-precision leak valve.

STM measurements were performed at room temperature using an Omicron UHV-STM-1 instrument in constant current mode with electrochemically etched tungsten tips. The base pressure was below $10^{-10}$ mbar.

XPS and TPD measurements were performed in a second vacuum system (base pressure $5 \times 10^{-11} \mathrm{mbar}$ ). XPS spectra were measured using a SPECS FOCUS 500 monochromatic source $(\mathrm{Al} \mathrm{K \alpha})$ and a SPECS PHOIBOS
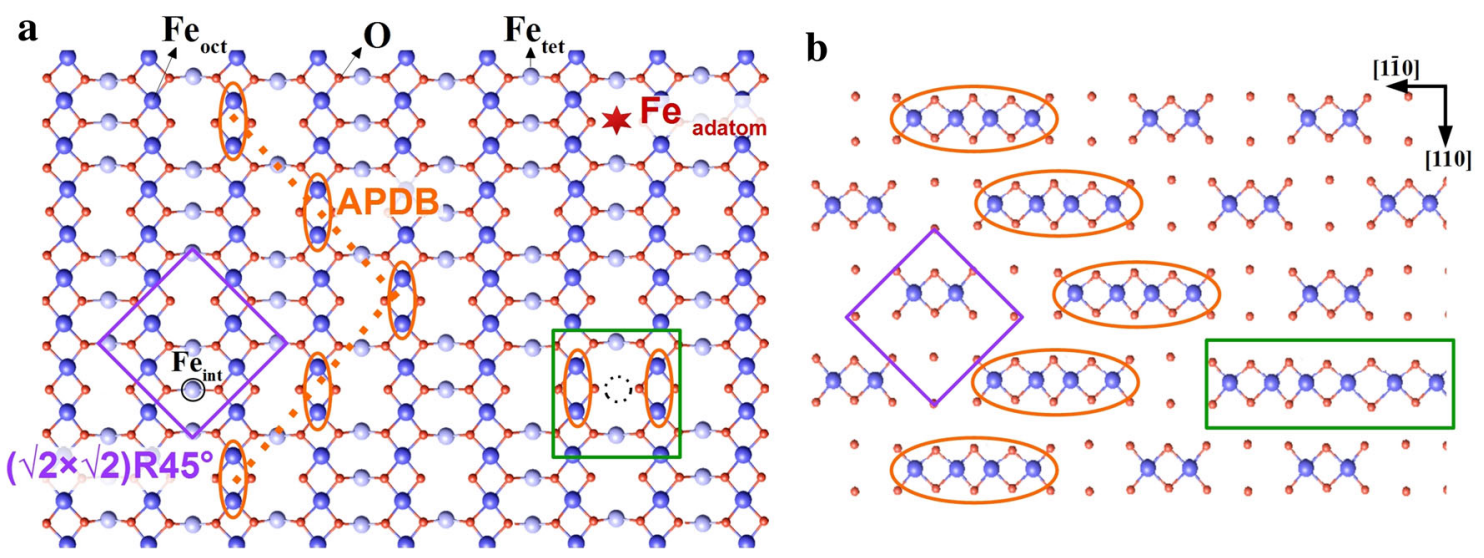

Fig. 1 Defects at the $\mathrm{Fe}_{3} \mathrm{O}_{4}(001)-(\sqrt{ } 2 \times \sqrt{ } 2) \mathrm{R} 45^{\circ}$ surface. The outermost two layers of the $\mathrm{Fe}_{3} \mathrm{O}_{4}(001)-(\sqrt{ } 2 \times \sqrt{ } 2) \mathrm{R} 45^{\circ}$ surface are shown in $\mathbf{a}$ and the third layer in $\mathbf{b}$. The $(\sqrt{2} \times \sqrt{2}) \mathrm{R} 45^{\circ}$ unit cell, indicated by the purple square, contains four $\mathrm{Fe}_{\text {oct }}$ atoms (big balls, dark blue) and eight $\mathrm{O}$ atoms (small balls, red) in the surface layer, and three $\mathrm{Fe}_{\text {tet }}$ atoms in the second layer (big balls, light blue). The $\mathrm{Fe}_{\text {tet }}$ indicated by the black circle is an interstitial $\left(\mathrm{Fe}_{\text {int }}\right)$ linked to the subsurface cation vacancy (SCV) reconstruction [16]. The interstitial replaces two $\mathrm{Fe}_{\text {oct }}$ atoms in the third layer, such that there is only two $\mathrm{Fe}_{\text {oct }}$ per unit cell instead of four. The dotted orange line indicates an antiphase domain boundary (APDB) in the SCV reconstruction. The pairs of surface $\mathrm{Fe}_{\text {oct }}$ atoms indicated by orange ovals at the boundary appear bright in STM images. Note that four $\mathrm{Fe}_{\text {oct }}$ are present in a row in the third layer beneath the APDB (see panel b). The green boxes highlight a defect in which an additional $\mathrm{Fe}_{\text {oct }}$ atom is incorporated in the third layer, which causes $\mathrm{Fe}_{\text {int }}$ to relocate to the other $\mathrm{Fe}_{\text {oct }}$ vacancy position. Note that because six $\mathrm{Fe}_{\text {oct }}$ are present in a row in the third layer beneath this defect, it appears as a double protrusion in STM images (orange ovals). The black dashed circle represent the position for a missing $\mathrm{Fe}_{\text {int }}$ in the second layer. The red star represents a possible position of an $\mathrm{Fe}$ adatom 
150 electron analyzer at normal emission with a pass energy of $16 \mathrm{eV}$. TPD experiments were performed using a HIDEN HAL/3F RC 301 PIC quadrupole mass spectrometer (QMS). The sample was cooled by a Janis ST-400 UHV liquid-He flow cryostat, and heated by direct current at a rate of $1 \mathrm{~K} / \mathrm{s}$ through a Ta back plate, on which the sample was mounted. The temperature was measured by a K-type thermocouple, and the sample was biased at $-100 \mathrm{~V}$ during TPD measurements to prevent electrons from the QMS filament from reaching the sample. For the TPD and XPS measurements, methanol was dosed using a home-built effusive molecular beam source, which enables precise and reproducible exposures to a defined area on the sample surface [19].

\section{Results}

\subsection{Defects on the As-Prepared Surface}

Figure 2a shows an STM image of the as-prepared $\mathrm{Fe}_{3} \mathrm{O}_{4}(001)$ surface. Rows of protrusions separated by $5.9 \AA$ are due to fivefold-coordinated surface iron atoms (the dark blue balls in Fig. 1a) within the SCV reconstruction [16]. Surface oxygen atoms (red in Fig. 1a) are not imaged as there are no O-derived states in the vicinity of the Fermi level [16]. A step edge runs across the centre of the image from left to right, separating two adjacent terraces (yellow arrow). The apparent step height of $2.1 \AA$ corresponds to the spacing between equivalent planes in the bulk structure [20] (i.e., the first and third layer in Fig. 1). Note that the direction of the iron rows rotates $90^{\circ}$ when going from one terrace to the next [20], consistent

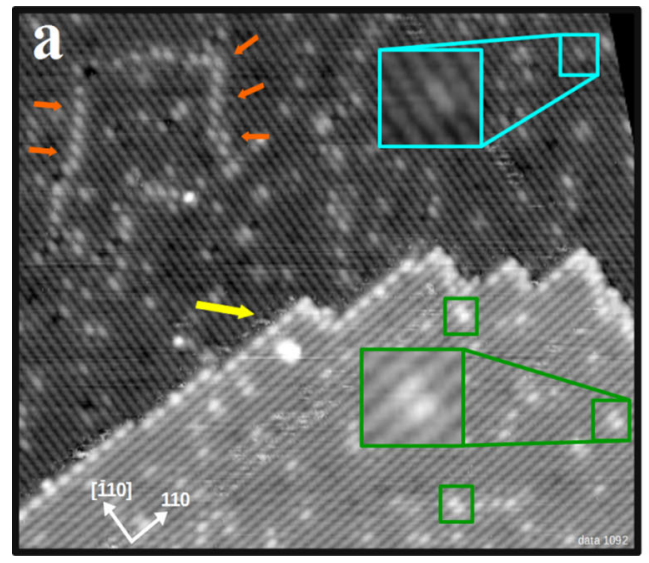

Fig. 2 STM images of the same spot on the $\mathrm{Fe}_{3} \mathrm{O}_{4}(001)$ surface before and after exposure to $\mathrm{CH}_{3} \mathrm{OH}$ at room temperature. a The asprepared $\mathrm{Fe}_{3} \mathrm{O}_{4}(001)-(\sqrt{ } 2 \times \sqrt{ } 2) \mathrm{R} 45^{\circ}$ surface $\left(39 \times 31 \mathrm{~nm}^{2}\right.$; $\left.\mathrm{V}_{\text {sample }}=+1.7 \mathrm{~V} ; \mathrm{I}_{\text {tunnel }}=0.3 \mathrm{nA}\right)$ with typical defects labeled as follows (see also Fig. 1 for a schematic): An APDB is visible as a row of protrusions in the lower terrace (indicated by the orange arrows). with the inverse spinel structure of magnetite. As reported previously [20], steps that run parallel to the Fe rows on the upper terrace are generally straight, whereas perpendicular steps are often jagged.

A second, extended defect that is frequently observed on the freshly prepared surface is the antiphase domain boundary (APDB) [21], indicated by orange arrows in Fig. 2a. This feature appears as a chain of bright protrusions located on the $\mathrm{Fe}_{\text {oct }}$ rows, and is typically aligned at $45^{\circ}$ with respect to the row direction (see also Fig. 1a) [21]. The APDBs probably arise because the $(\sqrt{ } 2 \times \sqrt{ } 2) \mathrm{R} 45^{\circ}$ reconstruction is lifted during each annealing cycle [22], and then renucleates on cooling through $723 \mathrm{~K}$ with one of two distinct registries with respect to the underlying bulk. It was noted previously [21] that the APDB forms such that two "narrow" sites (i.e., sites without 2 nd-layer $\mathrm{Fe}_{\text {tet }}$ in the SCV model) of the reconstruction meet at the interface. In the light of the SCV reconstruction [16], this preference can be reinterpreted as four $\mathrm{Fe}_{\text {oct }}$ atoms in a row in the third layer (as illustrated in Fig. 1b). The alternative scenario with four $\mathrm{Fe}$ vacancies at the interface in the third layer would create twofold-coordinated $\mathrm{O}$ atoms, which is expected to be unfavourable. Interestingly, with no $\mathrm{Fe}_{\text {int }}$ in the second layer and four $\mathrm{Fe}_{\text {oct }}$ atoms in a row in the third layer, the local structure at the APDB is akin to a bulk truncated surface.

In addition to the line defects, two types of point defects are observed (Fig. 2a). Surface hydroxyl groups appear in STM as bright protrusions located on the Fe rows (cyan box). These species were initially identified through the adsorption of atomic $\mathrm{H}$ on this surface [23], and have also been observed following dissociative adsorption of water [21]. They are easily distinguished

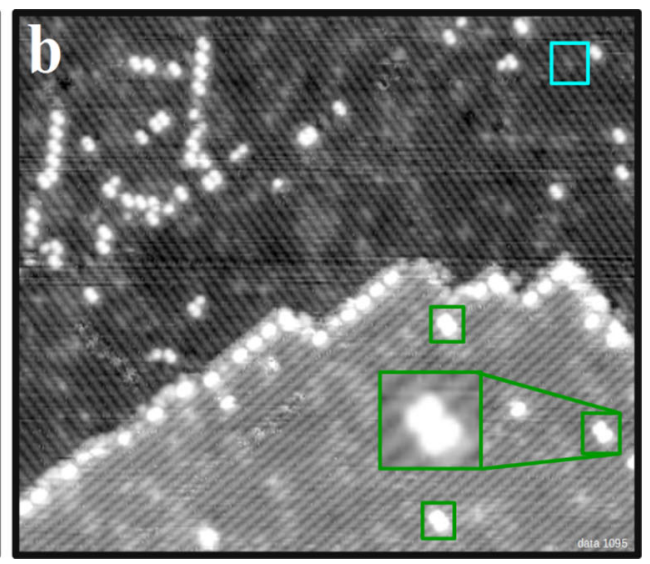

The bright protrusion on the Fe rows highlighted by the cyan box is due to a surface hydroxyl. The green boxes highlight pairs of bright features located on neighboring $\mathrm{Fe}$ rows, attributed to additional subsurface $\mathrm{Fe}$. b Exposure to $20 \mathrm{~L} \mathrm{CH}_{3} \mathrm{OH}$ at room temperature results in bright protrusions located on defects 
from other defects as they exhibit a characteristic hopping between opposite Fe rows in STM movies collected at room temperature $[18,21,23]$. It is important to note that the $\mathrm{OH}$ group is a $\mathrm{H}$ atom adsorbed on a surface $\mathrm{O}$ atom, albeit it appears as increased brightness of a pair on adjacent $\mathrm{Fe}$ atoms. This is an electronic effect, as the $\mathrm{OH}$ donates charge to the neighboring Fe atoms, which makes them brighter in STM [18]. Finally, the green boxes highlight pairs of bright features located on neighboring Fe rows. At first glance these features appear similar to hydroxyl groups, but they have a different apparent height (50 pm, compared to $20 \mathrm{pm}$ for the $\mathrm{OH}$ ) and they do not exhibit the characteristic hopping behavior described above. In the next section, we demonstrate that these defects are linked to $\mathrm{Fe}$ incorporated in the subsurface.

When the surface shown in Fig. 2a is exposed to $20 \mathrm{~L}$ of $\mathrm{CH}_{3} \mathrm{OH}$ at room temperature new features appear at some of the defects. The defects do not change their positions, but the apparent height of some defects increases significantly. For example, the bright features located on neighboring iron rows are now $150 \mathrm{pm}$ high, as compared to the $50 \mathrm{pm}$ previously, see also the line profiles in Fig. 3, below. Interestingly, the methanol-induced, bright features

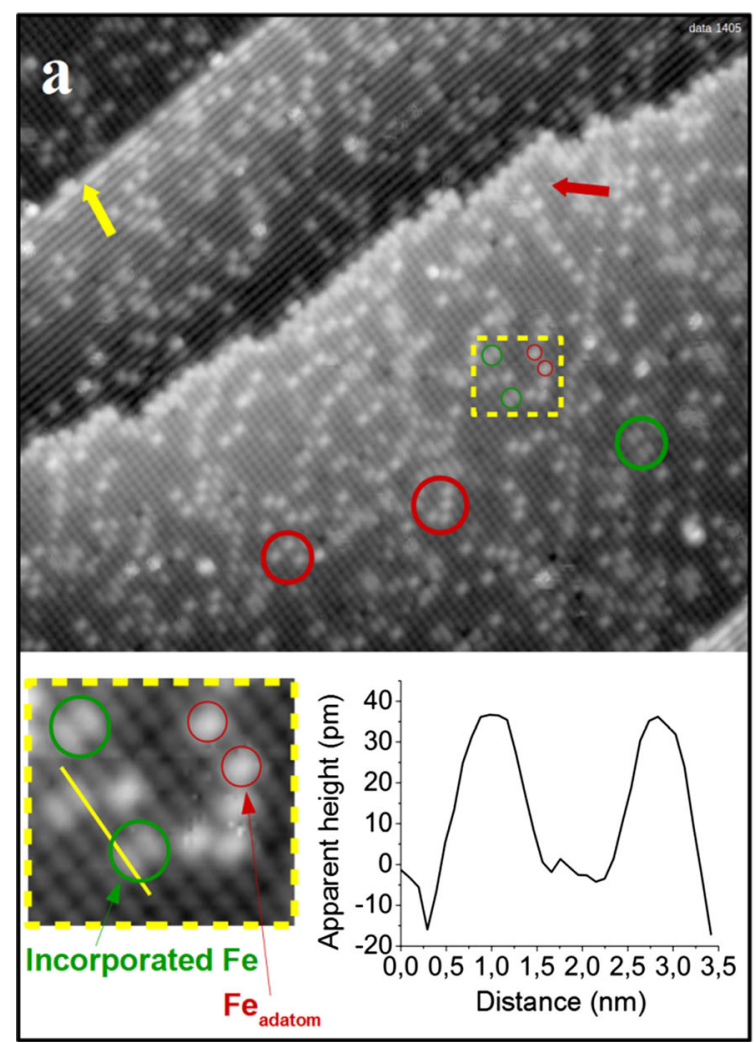

Fig. 3 STM images of the same area of an Fe-rich $\mathrm{Fe}_{3} \mathrm{O}_{4}(001)$ surface before and after exposure to $\mathrm{CH}_{3} \mathrm{OH}$ at room temperature. a The as-prepared $\mathrm{Fe}_{3} \mathrm{O}_{4}(001)-(\sqrt{ } 2 \times \sqrt{ } 2) \mathrm{R} 45^{\circ}$ surface modified by deposition of $0.1 \mathrm{ML} F \mathrm{Fe}\left(48 \times 45 \mathrm{~nm}^{2} ; \quad \mathrm{V}_{\text {sample }}=+1.7 \mathrm{~V}\right.$; $\mathrm{I}_{\text {tunnel }}=0.3 \mathrm{nA}$ ). $\quad \mathrm{Fe}$ adsorbs as adatoms (red circles) and were sometimes observed to disappear as the surface was scanned with the STM tip at room temperature, and the defects assumed their original appearance. However, because methanol was still present in the residual gas following the initial exposure, re-adsorption at defects was also observed.

\section{2 $\mathrm{Fe}_{3} \mathrm{O}_{4}(001)-(\sqrt{ } 2 \times \sqrt{ } 2) \mathrm{R45}^{\circ}$ with Additional Cation Defects}

To create an increased coverage of defects, 0.1 monolayer (ML) of Fe was deposited on the as-prepared SCV surface at room temperature, see Fig. 3a. (Here $1 \mathrm{ML}$ is defined as one atom per $(\sqrt{ } 2 \times \sqrt{ } 2) \mathrm{R} 45^{\circ}$ unit cell, i.e., $1.42 \times 10^{14}$ atoms $/ \mathrm{cm}^{2}$ ). This procedure results in $\mathrm{Fe}$ adatoms, as observed previously [24], which appear as bright protrusions between the Fe rows (red circles, see also the red star in the schematic in Fig. 1). The formation of stable adatoms is a distinctive property of the $\mathrm{Fe}_{3} \mathrm{O}_{4}(001)-(\sqrt{ } 2 \times \sqrt{ } 2) \mathrm{R} 45^{\circ}$ surface and has been observed for many different elements [refs. 25-29]. The appearance of the $\mathrm{Fe}$ protrusions is similar to those

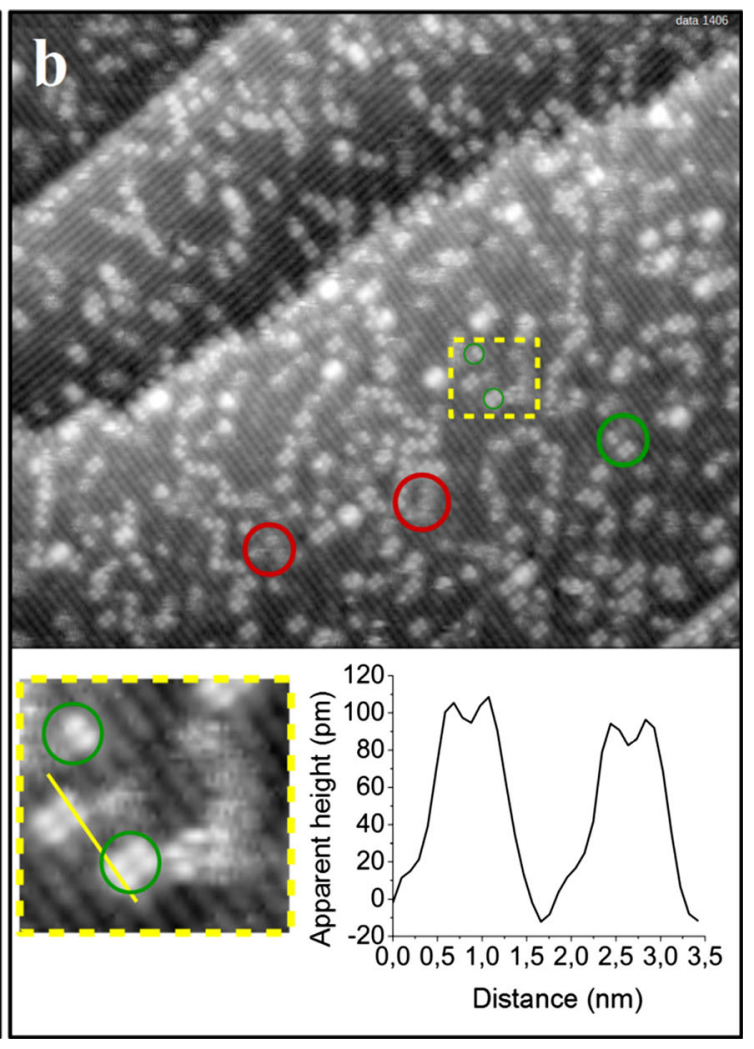

incorporates in the subsurface, forming bright double features on the $\mathrm{Fe}_{\mathrm{oct}}$ rows (green circles), see inset. b After exposure to $\mathrm{CH}_{3} \mathrm{OH}$, defects have a larger apparent height (see line profiles); the fuzzy appearance of the species on top of Fe adatoms indicate weakly adsorbed molecules 
observed for adatoms of $\mathrm{Au}, \mathrm{Ag}$ and $\mathrm{Pd}$ [25-27]. In addition, the density of the bright double features located on neighboring iron rows increases significantly upon $\mathrm{Fe}$ deposition (green circles). Similar features have been observed following the deposition of $\mathrm{Ni}, \mathrm{Co}, \mathrm{Ti}$ and $\mathrm{Zr}$ [28]. It is known that these elements enter the subsurface, filling one $\mathrm{Fe}_{\text {oct }}$ vacancy in the third layer of the SCV reconstruction, which induces the $\mathrm{Fe}_{\text {int }}$ to move and occupy the other. At $1 \mathrm{ML}$ coverage this results in a $(1 \times 1)$ symmetry. By analogy, it is natural to propose that deposited $\mathrm{Fe}$ atoms also enter the surface, and locally lift the SCV reconstruction. In the case of $\mathrm{Ni}$, the bright protrusion associated with the defect was found to appear above the two third-layer $\mathrm{Fe}_{\text {oct }}$ atoms, rather than above the incorporated foreign metal cation [28]. In the case of $\mathrm{Fe}$ incorporation, two such sites are created resulting in two bright protrusions. Note that six adjacent $\mathrm{Fe}_{\mathrm{oct}}$ atoms are present in the third layer at such defects (green boxes in Fig. 1).

Exposing the surface shown in Fig. 3a to $20 \mathrm{~L} \mathrm{CH}_{3} \mathrm{OH}$ (Fig. 3b) leads to similar features as already shown in Fig. 2b. Adsorption occurs again at the step edges, APDBs, and the incorporated Fe defects. Frequently after methanol adsorption four distinct maxima are located at each incorporated $\mathrm{Fe}$ defect; two protrusions above each $\mathrm{Fe}_{\text {oct }}$ row (see zoomed areas and line scans in Fig. 3). This suggests that all four $\mathrm{Fe}_{\text {oct }}$ atoms affected by the subsurface modification can adsorb a methanol-related species. Along the row the separation of the maxima is $3 \AA$ (see line scan in Fig. 3), which is consistent with the separation of neighboring $\mathrm{Fe}_{\mathrm{oct}}$ atoms. The adsorption of methoxy groups in close proximity to this defect could promote the disproportionation reaction (Eq. 1).

In addition, fuzzy features appear at the position of the $\mathrm{Fe}$ adatoms (red circle). Such apparently noisy parts in STM images are typically associated with weakly bound adsorbates that move during the scan. As before, dynamic desorption and readsorption was observed while scanning the surface with the STM at room temperature.

As mentioned above, there are two kinds of step edges on the $\mathrm{Fe}_{3} \mathrm{O}_{4}(001)$ surface. The yellow arrow in Fig. 3a highlights a straight step edge, which runs parallel to the iron rows on the upper terrace. The second type, perpendicular to the octahedral iron rows, is more jagged (red arrow).

\subsection{XPS}

To investigate the nature of the observed protrusions we performed XPS experiments. Figure 4 shows $\mathrm{O} 1 s$ and $\mathrm{C} 1 s$ photoemission spectra that were recorded after the asprepared $\mathrm{Fe}_{3} \mathrm{O}_{4}(001)$ surface was exposed to $1.8 \mathrm{~L}$ of $\mathrm{CH}_{3} \mathrm{OH}$ at $65 \mathrm{~K}$, and subsequently annealed to progressively higher temperatures. The $\mathrm{O} 1 s$ spectra are shown in Fig. 4a. The clean $\mathrm{Fe}_{3} \mathrm{O}_{4}(001)$ surface exhibits a slightly asymmetric peak at $530.1 \mathrm{eV}$ due to the lattice oxygen in magnetite as reported previously [23, 29]. Adsorption of $1.8 \mathrm{~L} \mathrm{CH}_{3} \mathrm{OH}$ at $65 \mathrm{~K}$ and annealing to $95 \mathrm{~K}$ produces two additional signals. The shoulder on the highenergy side at approximately $531 \mathrm{eV}$ is consistent with both surface $\mathrm{OH}$ groups and methoxy species [30], while the peak at $533.1 \mathrm{eV}$ is attributed to molecular $\mathrm{CH}_{3} \mathrm{OH}$ [31]. Neither the shape nor position of the lattice oxygen peak is affected by methanol adsorption, only its intensity is reduced. As the sample is heated to progressively higher temperatures the molecular methanol desorbs first. By $280 \mathrm{~K}$, the intensity of the peak at $533.1 \mathrm{eV}$ has decreased from initially $32 \%$ to just $4 \%$. The signal from the lattice oxygen increases again.

A similar conclusion can be drawn from the $\mathrm{C} 1 s$ spectra shown in Fig. 4b. No detectable $C$ peak is present when the surface is freshly prepared, but following the adsorption of methanol at $65 \mathrm{~K}$ and annealing to $95 \mathrm{~K}$ a symmetric peak centered at $286.5 \mathrm{eV}$ appears. Upon heating this peak decreases in intensity. When the sample is heated to $280 \mathrm{~K}$, its intensity decreases notably and its position shifts to $286 \mathrm{eV}$. This suggests that molecular methanol desorbs below room temperature, leaving only adsorbed methoxy species at $280 \mathrm{~K}$. Methoxy generally has a lower $\mathrm{C} 1 s$ binding energy than methanol (e.g. on $\mathrm{ZnO}$ [32], $\mathrm{TiO}_{2}$ (110) [8], $\mathrm{TiO}_{2}$ (001) [33], $\mathrm{MgO}$ [34], and $\mathrm{CeO}_{2}$ (111) [31]) due to an increase in the electron density around the $\mathrm{C}$ atom when the hydroxyl proton is removed [32].

In order to quantitatively determine the methoxy coverage at $300 \mathrm{~K}$ from the XPS data we compared the $\mathrm{C} 1 s$ peak area shown in Fig. $4 \mathrm{~b}$ to that of the same surface exposed to a saturation coverage of formic acid (not shown). We have previously shown that formic acid exposure results in a complete monolayer of formate with a density of $2.84 \times 10^{14}$ molecules $/ \mathrm{cm}^{2}$, or 2 molecules per $(\sqrt{ } 2 \times \sqrt{ } 2) R 45^{\circ}$ unit cell [17]. Since both molecules contain just one $\mathrm{C}$ atom, the formate:methoxy ratio of 1:0.0283 suggests a methoxy coverage of $8.05 \times 10^{12}$ molecules $/ \mathrm{cm}^{2}$. Such a low coverage is consistent with the defect-only adsorption observed by STM in Fig. 2.

In keeping with the STM experiments, we also performed XPS measurements for a surface on which the defect concentration was enhanced by deposition of $0.3 \mathrm{ML}$ Fe. Figure 5a compares the $\mathrm{Fe} 2 p$ spectra obtained before and after the deposition of the $\mathrm{Fe}$ (no methanol exposure). As shown previously [24], the deposition of $\mathrm{Fe}$ on the $\mathrm{Fe}_{3} \mathrm{O}_{4}(001)$ surface results in an increase in the $\mathrm{Fe}^{2+}$ component at $708.7 \mathrm{eV}$ in the $\mathrm{Fe} 2 p_{3 / 2}$ peak (compare inset in Fig. 5a). Adsorption of $10 \mathrm{~L}$ methanol at $280 \mathrm{~K}$ has no effect on the $\mathrm{Fe} 2 p$ spectrum for the clean or Fe rich surface (not shown) and also little effect on the O1s region (not shown). In the 

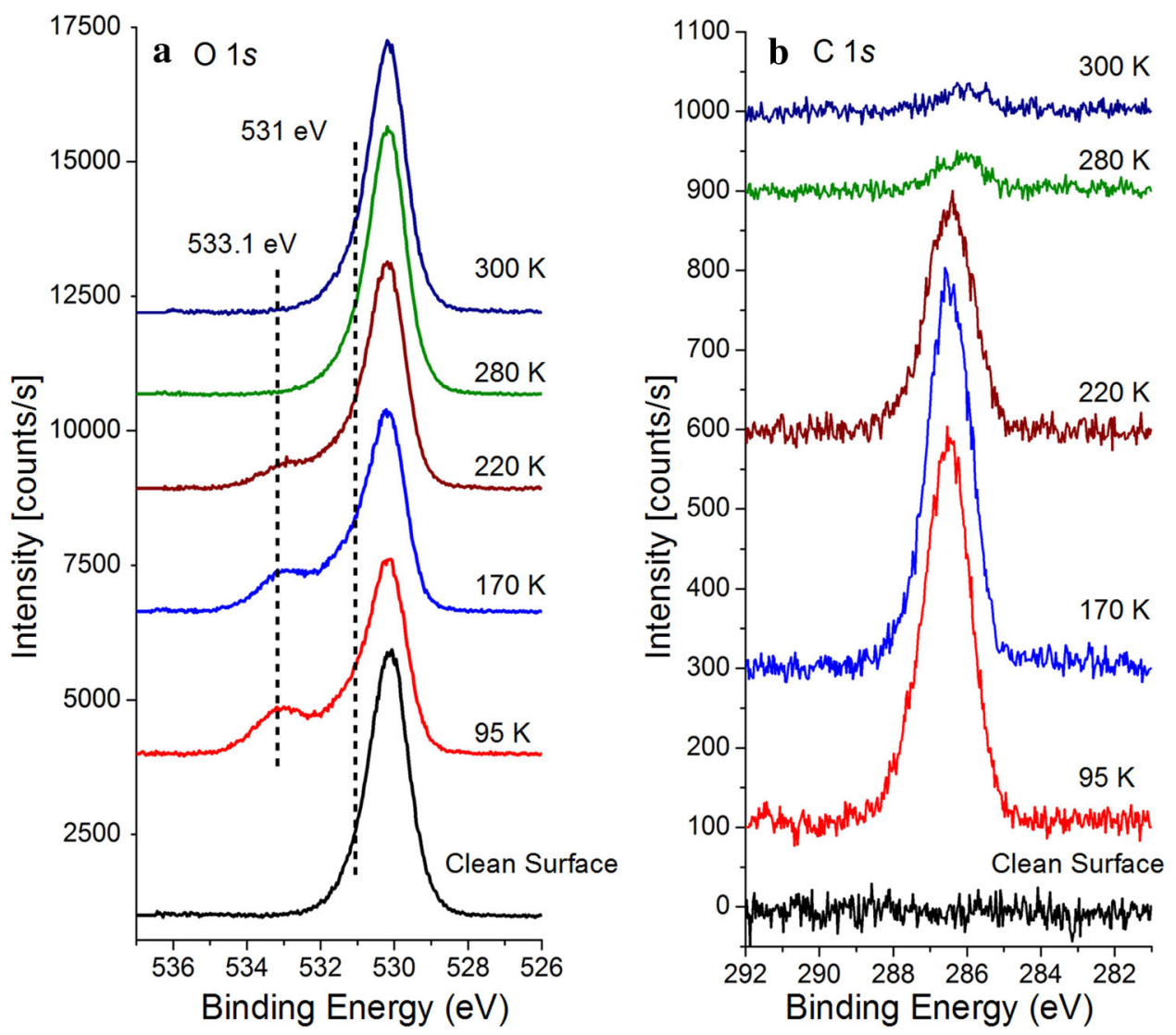

Fig. $4 \mathrm{O} 1 s$ and $\mathrm{C} 1 s$ XPS spectra from methanol adsorbed on the $\mathrm{Fe}_{3} \mathrm{O}_{4}(001)-(\sqrt{ } 2 \times \sqrt{ } 2) \mathrm{R} 45^{\circ}$ surface at $65 \mathrm{~K}$ and annealed as indicated. The data are offset in the y-direction for clarity

$\mathrm{C} 1 s$ region (Fig. 5b) however, a peak appears at $286.1 \mathrm{eV}$ on the clean surface, related to adsorption on defects. Heating to $300 \mathrm{~K}$ decreases this peak's intensity, while it remains at the same position. On the Fe deposited surface (blue), a peak appears at $286.3 \mathrm{eV}$, the integral of which is $50 \%$ larger than that obtained on the clean $\mathrm{Fe}_{3} \mathrm{O}_{4}(001)$ surface. Again, heating to $300 \mathrm{~K}$ decreases the intensity of the peak, which remains at the same position.

The $\mathrm{C} 1 s$ spectra show a small shift in the binding energies between the $0.3 \mathrm{ML} \mathrm{Fe}-\mathrm{Fe}_{3} \mathrm{O}_{4}(001)$ surface and the clean $\mathrm{Fe}_{3} \mathrm{O}_{4}(001)$ surface. This shift may be related to changes in the valence charge on the carbon due to changes in the electronegativity of the vicinity. Such an interpretation was suggested for similar differences between oxidized and reduced cerium oxide thin films [31], where the peak position on the reduced surface is shifted to higher binding energy. Alternatively, there may be a contribution from molecular methanol adsorbed on Fe adatoms.

\subsection{TPD}

Temperature programmed desorption was performed following the adsorption of $10 \mathrm{~L} \mathrm{CH}_{3} \mathrm{OH}$ at $280 \mathrm{~K}$ on the clean $\mathrm{Fe}_{3} \mathrm{O}_{4}(001)$ surface (Fig. 6a) and on the $0.3 \mathrm{ML}$
$\mathrm{Fe}-\mathrm{Fe}_{3} \mathrm{O}_{4}(001)$ surface (Fig. 6b). Desorption of methanol was monitored by following mass 31 (red dots), which is the most intense cracking fragment of this molecule. By comparing this signal with mass 29 (black dots), possible reaction products can be determined [5]. On the pristine surface, the TPD spectra exhibit two peaks; a sharp peak at $335 \mathrm{~K}$, and a broad shoulder in the region between 400 and $580 \mathrm{~K}$. While the peak at $335 \mathrm{~K}$ has a similar shape and intensity for both masses, indicative of molecular methanol, the signal in the region between 400 and $580 \mathrm{~K}$ is higher for mass 29 . With the addition of $0.3 \mathrm{ML} \mathrm{Fe}$, the low-temperature peak at $335 \mathrm{~K}$ slightly shifts to $320 \mathrm{~K}$, and its intensity increases by $42 \%$. As before, the intensity and line shape is similar for both mass 29 and 31 . In the region between 400 and $580 \mathrm{~K}$, the peak for mass 31 has its maximum at $450 \mathrm{~K}$, while the peak for mass 29 , which is significantly sharper, has the maximum intensity at $470 \mathrm{~K}$. The blue curves in Fig. 6 result from subtracting the smoothed signal for mass 31 from the smoothed mass 29 spectrum. This procedure removes the contribution of methanol from the mass 29 signal, leaving only that of formaldehyde. For the clean $\mathrm{Fe}_{3} \mathrm{O}_{4}(001)-(-$ $\sqrt{ } 2 \times \sqrt{ } 2) \mathrm{R} 45^{\circ}$ surface a broad peak is observed with a peak at $480 \mathrm{~K}$, which is increased in intensity following the deposition of 0.3 ML Fe. 

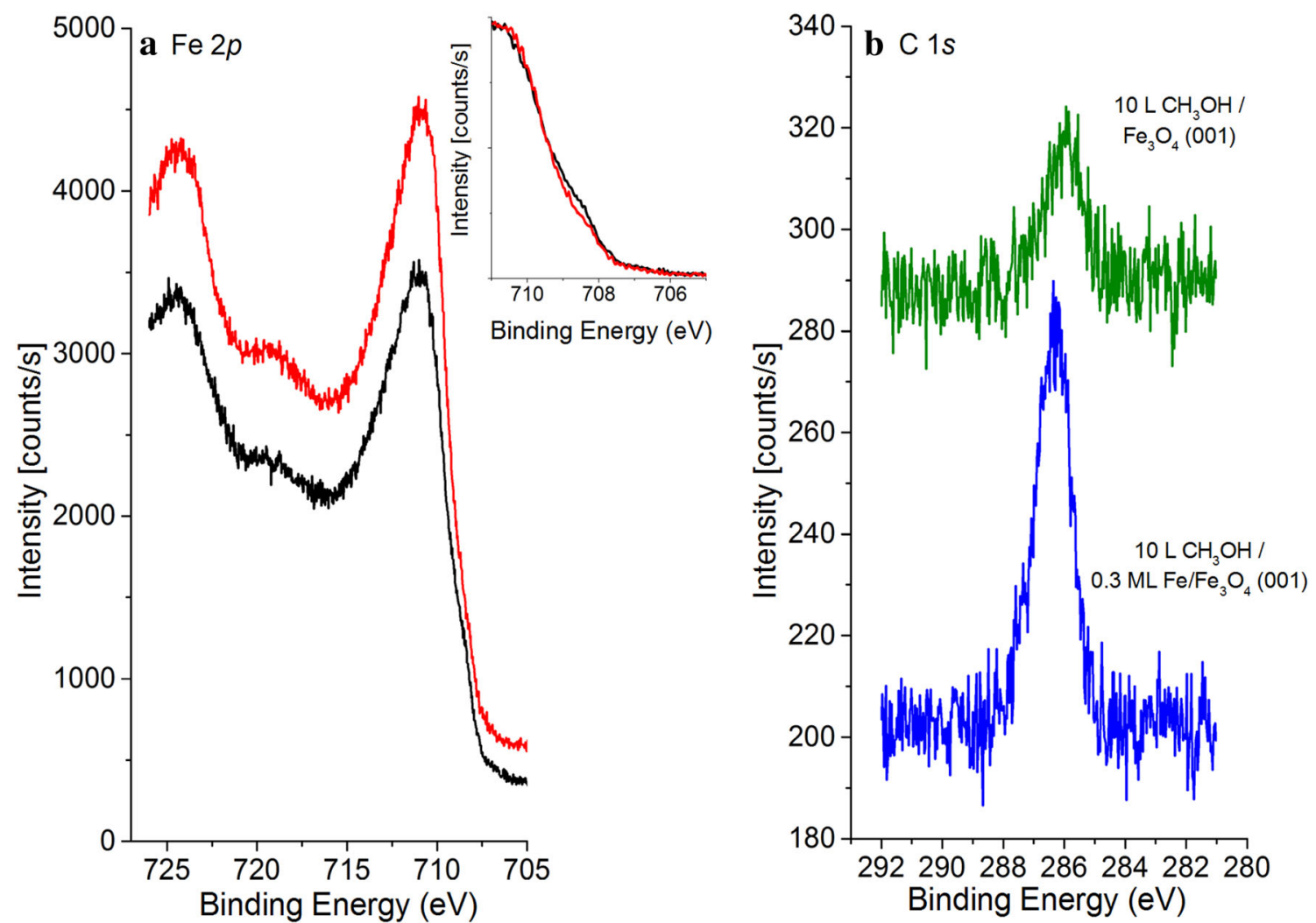

Fig. 5 a $\mathrm{Fe} 2 p$ XPS spectra before (red) and after (black) the deposition of $0.3 \mathrm{ML} \mathrm{Fe}$ on the clean $\mathrm{Fe}_{3} \mathrm{O}_{4}(001)-(\sqrt{ } 2 \times \sqrt{ } 2) \mathrm{R} 45^{\circ}$ surface at room temperature. b C $1 s$ XPS spectra from methanol

adsorbed at $280 \mathrm{~K}$ on the $\mathrm{Fe}_{3} \mathrm{O}_{4}(001)-(\sqrt{ } 2 \times \sqrt{ } 2) \mathrm{R} 45^{\circ}$ surface (green line) and the $0.3 \mathrm{ML} \mathrm{Fe} / \mathrm{Fe}_{3} \mathrm{O}_{4}(001)-(\sqrt{2} \times \sqrt{2}) \mathrm{R} 45^{\circ}$ surface (blue line). The data are offset in the $\mathrm{y}$-direction for clarity
Fig. 6 TPD spectra of $10 \mathrm{~L}$ of $\mathrm{CH}_{3} \mathrm{OH}$ dosed at $280 \mathrm{~K}$.

a $\mathrm{Fe}_{3} \mathrm{O}_{4}(001)-(\sqrt{ } 2 \times \sqrt{ } 2) \mathrm{R} 45^{\circ}$ surface; b $0.3 \mathrm{ML} \mathrm{Fe}-$ $\mathrm{Fe}_{3} \mathrm{O}_{4}(001)-(\sqrt{ } 2 \times \sqrt{ } 2) \mathrm{R} 45^{\circ}$ surface. The data are offset in the y-direction for clarity. The blue curve, calculated by subtracting the smoothed signal from mass 29 from that of the smoothed signal of mass 31 , represents the desorption of formaldehyde
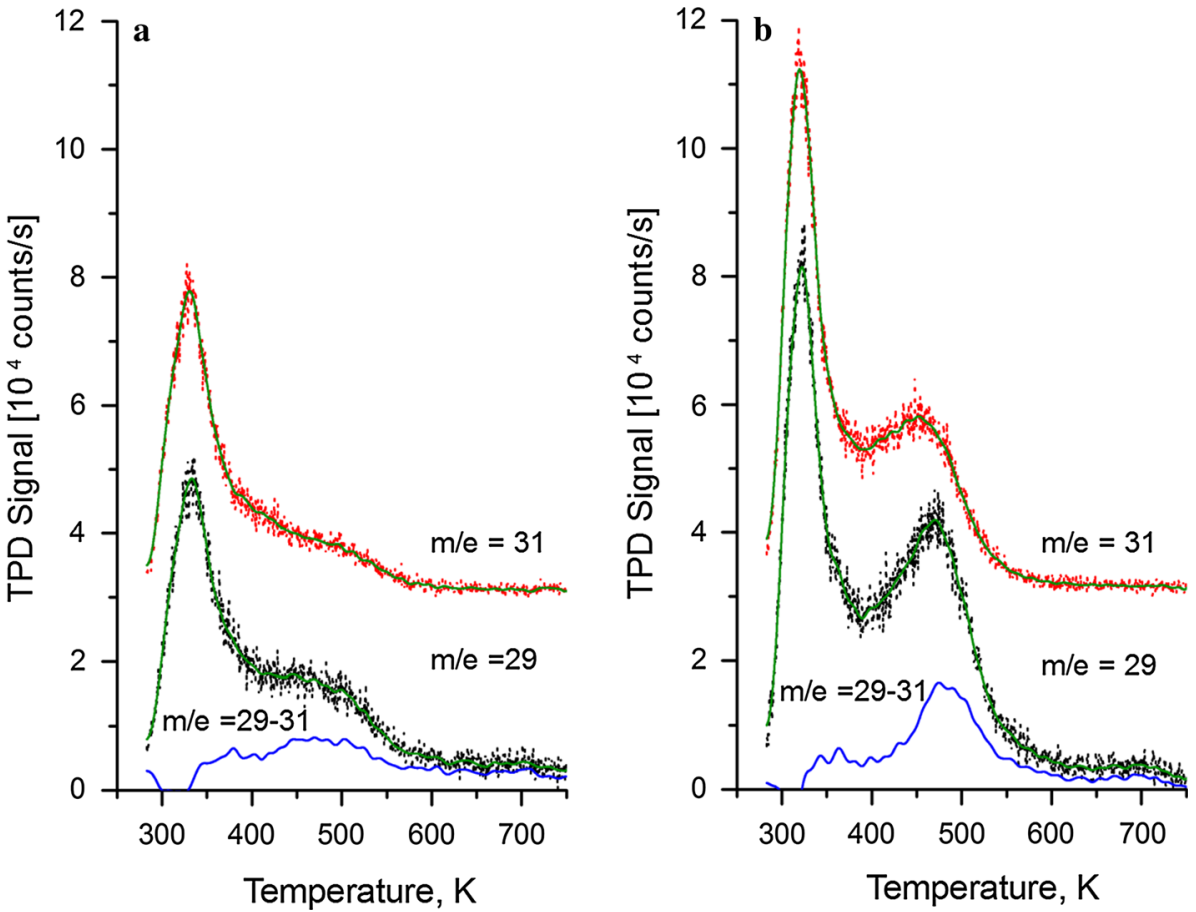
The peak at $480 \mathrm{~K}$ is thus attributable to desorption of formaldehyde, as observed previously, albeit at higher temperature, on $\mathrm{Fe}_{3} \mathrm{O}_{4}(111)$ [14]. The mass spectra show no evidence for $\mathrm{CH}_{4}$ or $\mathrm{C}_{\mathrm{X}} \mathrm{H}_{\mathrm{Y}}$, which would have been related to $\mathrm{C}-\mathrm{O}$ bond cleavage [35]. Evolution of $\mathrm{CO}$ and $\mathrm{H}_{2}$ was also not observed.

\section{Discussion}

\subsection{Adsorption at Defects}

On the basis of the STM, XPS and TPD results described above it is clear that methanol adsorption is restricted to defect sites on the $\mathrm{Fe}_{3} \mathrm{O}_{4}(001)$ surface at room temperature. This is in contrast to formic acid, which was previously found to dissociate at regular lattice sites on this surface, resulting in a monolayer of bidentate formate species [17]. That the surface dissociates formic acid suggests that the cation-anion site separation is not prohibitive, but rather the acid-base strength of the surface atoms is insufficient to induce dissociation of weaker acids, such as methanol. On the basis of the STM data the active sites for dissociation are identified as step edges, $\mathrm{Fe}$ adatoms, incorporated Fe defects, and APDBs; we discuss these in turn in the following.

The reactivity of step edges on metal oxide surfaces is well documented [4, 36, 37], and is linked to the coordinative unsaturation of the atoms located there. In the present case, the step edge structures are not definitively known, so the discussion in the following must be limited to simple models of the step edges, not taking any possible reconstruction into account.

Following the procedure of Henrich [20], we have reevaluated the step stability in terms of covalent stability (coordinative unsaturation) for the $\mathrm{SCV}$ reconstructed surface. The most stable step parallel to the $\mathrm{Fe}_{\text {oct }}$ rows (denoted $\mathrm{B}-\alpha^{*}$ by Henrich) exposes $\mathrm{Fe}_{\text {tet }}$ atoms with only one dangling bond each (Fig. 7a). All other configurations expose $\mathrm{Fe}_{\text {oct }}$ atoms with three dangling bonds at each atom, which are likely more reactive. Perpendicular to the rows several different configurations are similarly stable, and all expose both, $\mathrm{Fe}_{\mathrm{oct}}$ atoms with three dangling bonds per atom, and $\mathrm{Fe}_{\text {tet }}$ atoms, which have two dangling bonds (one example is shown in Fig. 7b). The higher coordinative unsaturation of cations at the perpendicular steps likely makes these sites reactive.

This suggests that the perpendicular steps should be more reactive, as they expose Fe with higher coordinative unsaturation. However, our results showed some degree of reactivity for both kind of steps to methanol adsorption, as observed in Figs. 2 and 3.

$\mathrm{Fe}$ adatoms are not a common defect when the $\mathrm{Fe}_{3} \mathrm{O}_{4}(001)$ surface is annealed in oxygen, but they become more prevalent when the surface is prepared in reducing conditions [38], when the $\mathrm{Fe}_{3} \mathrm{O}_{4}$ bulk is Fe-rich [39, 40], or when $\mathrm{Fe}$ is evaporated onto the surface [24]. The reactivity of the $\mathrm{Fe}$ adatoms is again most likely linked to coordinative unsaturation, because such cations have only two bonds to surface oxygen. The fuzzy appearance of the adsorbed methanol (inset Fig. 3), which indicates mobility underneath the STM tip, could mean that the molecule is adsorbed more weakly as compared to the other defects. This is possibly because dissociation of the molecule is precluded by the lack of undercoordinated lattice oxygen nearby that can receive the acid proton. Previous experimental and theoretical studies have found that adsorption of $\mathrm{H}$ is energetically unfavorable for an $\mathrm{O}_{\text {surface }}$ with a subsurface $\mathrm{Fe}_{\text {tet }}$ neighbor [41].

In addition to $\mathrm{Fe}$ adatoms, this paper reports a new defect linked to excess Fe that appears in STM as a pair of bright protrusions on opposite $\mathrm{Fe}_{\mathrm{oct}}$ rows. The density of such defects scales with the amount of deposited Fe, and resembles protrusions observed following incorporation of $\mathrm{Ni}, \mathrm{Ti}$ and $\mathrm{Co}$ atoms in the subsurface vacancies of the $\mathrm{SCV}$ reconstruction [28]. By analogy, it is proposed that deposited Fe atoms can enter the subsurface and occupy one of the $\mathrm{Fe}_{\text {oct }}$ vacancies present in the third layer. This induces the $\mathrm{Fe}_{\text {int }}$ interstitial to move and occupy the other $\mathrm{Fe}_{\text {oct }}$ site, resulting in a structure that locally resembles a bulk-truncated $\mathrm{Fe}_{3} \mathrm{O}_{4}$ lattice. It is interesting that such a defect would be reactive, because the surface layer of the bulk truncated surface should differ little from that of the SCV reconstruction, save for some small relaxations $(<0.1 \AA)$. The coordinative unsaturation of the $\mathrm{Fe}$ and $\mathrm{O}$ atoms is the same, and DFT $+\mathrm{U}$ calculations predict that both surfaces contain only $\mathrm{Fe}^{3+}$-like cations in the surface layer [16]. A key difference affecting reactivity might be the local electronic structure: Density-of-states plots for the
Fig. 7 Structural models of step edges for the $\mathrm{Fe}_{3} \mathrm{O}_{4}(001)$ surface. a Steps parallel to the iron ion rows along $[1 \overline{1} 0](B-\alpha$ type). b Steps perpendicular to the iron ion rows along [110] (B- $\beta$ type). Labels after Ref. [20]
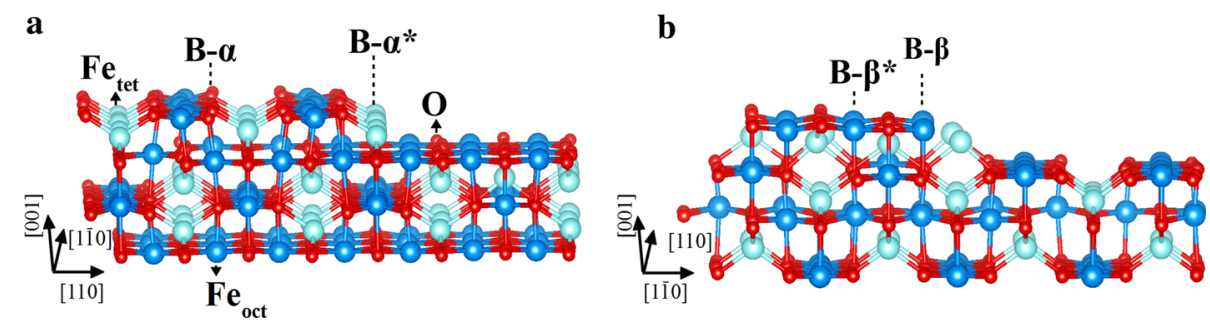
bulk truncation exhibit significantly greater density of (empty) states above the Fermi level than the SCV reconstruction due to $\mathrm{Fe}_{\mathrm{oct}}^{2+}$-like cations in the third layer [42, 43]. The presence of such states can make the region a stronger Lewis acid site, and more receptive to the electrons from the methoxy.

As discussed above, the APDB is an interruption of the vacancy-interstitial pattern in the second and third layers of the SCV reconstruction, and forms such that four $\mathrm{Fe}_{\mathrm{oct}}$ cations meet in the third layer at the junction (see Fig. 1). Locally, such a configuration also resembles again the unreconstructed lattice. Thus the reactivity can be explained in similar terms to the incorporated-Fe point defect.

\subsection{Reaction Channels for the Adsorption of $\mathrm{CH}_{3} \mathrm{OH}$ on $\mathrm{Fe}_{3} \mathrm{O}_{4}(001)$}

TPD analysis shows that for both surfaces, the signals for masses 29 and 31 match perfectly over the range between 280 and $350 \mathrm{~K}$. This is evidence that the peak around $300 \mathrm{~K}$ observed is due to desorption of $\mathrm{CH}_{3} \mathrm{OH}$ only [5]. Similar observations have been reported on $\mathrm{Fe}_{3} \mathrm{O}_{4}(111)$ [14] and $\mathrm{TiO}_{2}(110)$ [44], where peaks in the same range of desorption temperatures have been assigned to the recombinative desorption of $\mathrm{CH}_{3} \mathrm{OH}$. Deposition of Fe results in an increased desorption in this region, which may be linked to molecular methanol adsorbed at the $\mathrm{Fe}$ adatoms.

The increased desorption in the region between 400 and $580 \mathrm{~K}$ suggests that the adsorption of methanol increases in the presence of Fe-related defects. Following the behavior of the spectra for both masses, is clear that, in the hightemperature range, the intensity and the shape of both spectra are different; this observation indicates the presence of another species in addition to methanol. Specifically, mass 31 has a contribution from methanol, while mass 29 has contributions from both methanol and formaldehyde $\left(\mathrm{H}_{2} \mathrm{CO}\right)$; the latter is often observed as product of methanol reaction. Consequently, we assign the signal at high temperature as due to partial oxidation of methanol to formaldehyde.

Partial oxidation has been identified on other oxide surfaces as one of the main possible reactions. Interestingly, when the $\mathrm{Fe}_{3} \mathrm{O}_{4}(001)$ surface was modified to have additional $\mathrm{Fe}$ adatoms and incorporated $\mathrm{Fe}$ defects a similar increase was observed in the peak at $320 \mathrm{~K}$ and the hightemperature products linked to the disproportionation reaction (Eq. 1). Given the relative abundance of $\mathrm{Fe}$ adatoms and incorporated Fe defects (approx. 50:50 at 0.3 ML coverage), and the probability that the $\mathrm{Fe}$ adatoms cannot dissociate $\mathrm{CH}_{3} \mathrm{OH}$ and thus contributes to the lower temperature peak, it seems likely that the increase in formaldehyde production is due to the subsurface $\mathrm{Fe}$ defects. This can be because this defect promotes the disproportionation reaction by adsorbing two methoxy species in close proximity. Given the structural and electronic similarities between the incorporated $\mathrm{Fe}$ defect and the APDB, this defect also likely promotes the disproportionation reaction.

The temperature for the disproportionation reaction appears to depend on various factors such as the oxidation state of the metal oxide. In the case of vanadium oxide supported on $\mathrm{CeO}_{2}$, formaldehyde desorption curves have shown signals in temperature ranges from 500 to $610 \mathrm{~K}$, depending on the oxidation state of vanadium [45]. At the $\mathrm{CeO}_{2}(111)$ surface, methanol was oxidized to formaldehyde and water at $680 \mathrm{~K}$ after that methanol dissociation had occurred at oxygen vacancies [10]. On the other hand, complete dehydrogenation of methanol to $\mathrm{CO}$ and $\mathrm{H}_{2}$ has been reported on highly reduced ceria surfaces [9]. It is important to note that a similar chemistry occurs on the $\mathrm{Fe}_{3} \mathrm{O}_{4}(001)$ surface despite the lack of oxygen vacancies, and that defects related to excess $\mathrm{Fe}^{2+}$ play the important role. Given the available evidence it appears that the adsorption of multiple methoxy species in close proximity at the incorporated Fe defect may promote the disproportionation reaction.

\section{Conclusions}

We have studied the adsorption of methanol on the $\mathrm{Fe}_{3} \mathrm{O}_{4}(001)$ surface using TPD, STM and XPS. Methanol adsorbs dissociatively on $\mathrm{Fe}_{3} \mathrm{O}_{4}(001)$ at $280 \mathrm{~K}$ at defect sites that were identified as step edges, antiphase domain boundaries (APDB), iron adatoms and incorporated-Fe defects. Whereas adsorption at the steps and $\mathrm{Fe}$ adatoms can be explained in terms of coordinative unsaturation, reactivity at the $\mathrm{APDBs}$ and incorporated $\mathrm{Fe}$ defects is linked to the local electronic structure; specifically to the presence of $\mathrm{Fe}^{2+}$ cations in the surface layers. We propose that the adsorption of multiple methoxy species at the latter two defects promotes a disproportionation reaction to form methanol and formaldehyde.

Acknowledgments G.S.P., R.B., O.G., J.H., and J.P. acknowledge funding from the Austrian Science Fund START prize Y 847-N20 and project number P24925-N20. R.B. and O.G. acknowledge a stipend from the Vienna University of Technology and the Austrian Science Fund as part of the doctoral college SOLIDS4FUN (W1243). U.D. and J.P. acknowledge support by the European Research Council (Advanced Grant "OxideSurfaces"). M.S. was supported by the Austrian Science Fund (FWF) within SFB F45 "FOXSI". Open access funding provided by Austrian Science Fund (FWF).

Open Access This article is distributed under the terms of the Creative Commons Attribution 4.0 International License (http://crea tivecommons.org/licenses/by/4.0/), which permits unrestricted use, distribution, and reproduction in any medium, provided you give 
appropriate credit to the original author(s) and the source, provide a link to the Creative Commons license, and indicate if changes were made.

\section{References}

1. Palo DR, Dagle RA, Holladay JD (2007) Methanol steam reforming for hydrogen production. Chem Rev 107:3992-4021

2. Sá S, Silva H, Brandão L, Sousa JM, Mendes A (2010) Catalysts for methanol steam reforming-a review. Appl Catal B 99:43-57

3. Badlani M, Wachs IE (2001) Methanol: a "Smart" chemical probe molecule. Catal Lett 75:137-149

4. Vohs JM (2012) Site requirements for the adsorption and reaction of oxygenates on metal oxide surfaces. Chem Rev 113:4136-4163

5. Herman GS, Dohnálek Z, Ruzycki N, Diebold U (2003) Experimental investigation of the interaction of water and methanol with anatase- $\mathrm{TiO}_{2}$ (101). J Phy Chem B 107:2788-2795

6. Onda K, Li B, Zhao J, Petek H (2005) The electronic structure of methanol covered $\mathrm{TiO}_{2}(110)$ surfaces. Surf Sci 593:32-37

7. Zhang Z, Bondarchuk O, White JM, Kay BD, Dohnálek Z (2006) Imaging adsorbate $\mathrm{O}-\mathrm{H}$ bond cleavage: methanol on $\mathrm{TiO}_{2}(110)$. J Am Chem Soc 128:4198-4199

8. Farfan-Arribas E, Madix RJ (2003) Different binding sites for methanol dehydrogenation and deoxygenation on stoichiometric and defective $\mathrm{TiO}_{2}(110)$ surfaces. Surf Sci 544:241-260

9. Ferrizz RM, Wong GS, Egami T, Vohs JM (2001) Structure sensitivity of the reaction of methanol on ceria. Langmuir 17:2464-2470

10. Namai Y, K-i Fukui, Iwasawa Y (2004) The dynamic behaviour of $\mathrm{CH}_{3} \mathrm{OH}$ and $\mathrm{NO}_{2}$ adsorbed on $\mathrm{CeO}_{2}(111)$ studied by noncontact atomic force microscopy. Nanotechnology 15:S49

11. Peng XD, Barteau MA (1991) Acid-base properties of model magnesium oxide surfaces. Langmuir 7:1426-1431

12. Perrot E, Dayez M, Humbert A, Marti O, Chapon C, Henry CR (1994) Atomic-scale resolution on the $\mathrm{MgO}(100)$ surface by scanning force and friction microscopy. Europhys Lett 26:659

13. Rim KT, Eom D, Chan S-W, Flytzani-Stephanopoulos M, Flynn GW, Wen X, Batista E (2012) Scanning tunneling microscopy and theoretical study of water adsorption on $\mathrm{Fe}_{3} \mathrm{O}_{4}$ : implications for catalysis. J Am Chem Soc 134:18979-18985

14. Li Z, Potapenko DV, Rim KT, Flytzani-Stephanopoulos M, Flynn GW, Osgood R, Wen X, Batista E (2015) Reactions of deuterated methanol $\left(\mathrm{CD}_{3} \mathrm{OD}\right)$ on $\mathrm{Fe}_{3} \mathrm{O}_{4}(111)$. J Phys Chem $\mathrm{C}$ 119:1113-1120

15. Parkinson GS (2016) Iron oxide surfaces. Surf Sci Rep. 71:272-365

16. Bliem R, McDermott E, Ferstl P, Setvin M, Gamba O, Pavelec J, Schneider MA, Schmid M, Diebold U, Blaha P, Hammer L, Parkinson GS (2014) Subsurface cation vacancy stabilization of the magnetite (001) surface. Science 346:1215-1218

17. Gamba O, Noei H, Pavelec J, Bliem R, Schmid M, Diebold U, Stierle A, Parkinson GS (2015) Adsorption of formic acid on the $\mathrm{Fe}_{3} \mathrm{O}_{4}(001)$ surface. J Phys Chem C 119:20459-20465

18. Parkinson GS, Novotný Z, Jacobson P, Schmid M, Diebold U (2011) Room temperature water splitting at the surface of magnetite. J Am Chem Soc 133:12650-12655

19. Halwidl D (2016) Development of an effusive molecular beam apparatus. Springer, Spektrum

20. Wang H-Q, Altman EI, Henrich VE (2006) Steps on $\mathrm{Fe}_{3} \mathrm{O}_{4}(100)$ : STM measurements and theoretical calculations. Phys Rev B 73:235418

21. Parkinson GS, Manz TA, Novotný Z, Sprunger PT, Kurtz RL, Schmid M, Sholl D, Diebold U (2012) Antiphase domain boundaries at the $\mathrm{Fe}_{3} \mathrm{O}_{4}(001)$ surface. Phys Rev B 85:195450
22. Bartelt NC, Nie S, Starodub E, Bernal-Villamil I, Gallego S, Vergara L, McCarty K, de la Figuera J (2013) Order-disorder phase transition on the (100) surface of magnetite. Phys Rev B $88: 235436$

23. Parkinson GS, Mulakaluri N, Losovyj Y, Jacobson P, Pentcheva R, Diebold U (2010) Semiconductor-half metal transition at the $\mathrm{Fe}_{3} \mathrm{O}_{4}(001)$ surface upon hydrogen adsorption. Phys Rev B $82: 125413$

24. Novotny Z, Mulakaluri N, Edes Z, Schmid M, Pentcheva R, Diebold U, Parkinson GS (2013) Probing the surface phase diagram of $\mathrm{Fe}_{3} \mathrm{O}_{4}(001)$ towards the Fe-rich limit: evidence for progressive reduction of the surface. Phys Rev B 87:195410

25. Bliem R, Kosak R, Perneczky L, Novotny Z, Gamba O, Fobes D, Mao Z, Schmid M, Blaha P, Diebold U, Parkinson GS (2014) Cluster nucleation and growth from a highly supersaturated adatom phase: silver on magnetite. ACS Nano 8:7531-7537

26. Parkinson GS, Novotny Z, Argentero G, Schmid M, Pavelec J, Kosak J, Blaha P, Diebold U (2013) Carbon monoxide-induced adatom sintering in a Pd- $-\mathrm{Fe}_{3} \mathrm{O}_{4}$ model catalyst. Nat Mater 12:724-728

27. Novotný Z, Argentero G, Wang Z, Schmid M, Diebold U, Parkinson GS (2012) Ordered array of single adatoms with remarkable thermal stability: $\mathrm{Au} / \mathrm{Fe}_{3} \mathrm{O}_{4}(001)$. Phys Rev Lett 108:216103

28. Bliem R, Pavelec J, Gamba O, McDermott E, Wang Z, Osiecki J, Schulte K, Schmid M, Blaha P, Diebold U, Parkinson GS (2015) Adsorption and incorporation of transition metals at the magnetite $\mathrm{Fe}_{3} \mathrm{O}_{4}(001)$ surface. Phys Rev B 92:075440

29. Taguchi M, Chainani A, Ueda S, Matsunami M, Ishida Y, Eguchi R, Tsuda Y, Yabashi M, Tamasaku K, Nishino Y, Ishikawa T, Daimon H, Todo S, Tanaka H, Oura M, Senba Y, Ohashi H, Shin $S$ (2015) Temperature dependence of magnetically active charge excitations in magnetite across the Verwey transition. Phys Rev Lett 115:256405

30. Matolín V, Libra J, Škoda M, Tsud N, Prince KC, Skála T (2009) Methanol adsorption on a $\mathrm{CeO}_{2}(111) / \mathrm{Cu}(111)$ thin film model catalyst. Surf Sci 603:1087-1092

31. Mullins DR, Robbins MD, Zhou J (2006) Adsorption and reaction of methanol on thin-film cerium oxide. Surf Sci 600:1547-1558

32. Vohs JM, Barteau MA (1986) Conversion of methanol, formaldehyde and formic acid on the polar faces of zinc oxide. Surf Sci 176:91-114

33. Kim KS, Barteau MA (1989) Reactions of methanol on $\mathrm{TiO}_{2}(001)$ single crystal surfaces. Surf Sci 223:13-32

34. Peng XD, Barteau MA (1989) Spectroscopic characterization of surface species derived from $\mathrm{HCOOH}, \mathrm{CH}_{3} \mathrm{COOH}, \mathrm{CH}_{3} \mathrm{OH}$, $\mathrm{C}_{2} \mathrm{H}_{5} \mathrm{OH}, \mathrm{HCOOCH}_{3}$, and $\mathrm{C}_{2} \mathrm{H}_{2}$ on $\mathrm{MgO}$ thin film surfaces. Surf Sci 224:327-347

35. Mensch MW, Byrd CM, Cox DF (2003) Reaction of methanol on stoichiometric and O-terminated $\alpha-\mathrm{Cr}_{2} \mathrm{O}_{3}(10 \overline{1} 2)$ : interconversion of oxygenated $\mathrm{C} 1$ surface intermediates. Catal Today 85:279-289

36. Henrich VE, Shaikhutdinov SK (2005) Atomic geometry of steps on metal-oxide single crystals. Surf Sci 574:306-316

37. Gong X-Q, Selloni A, Batzill M, Diebold U (2006) Steps on anatase $\mathrm{TiO}_{2}(101)$. Nat Mater 5:665-670

38. Parkinson GS, Novotný Z, Jacobson P, Schmid M, Diebold U (2011) A metastable $\mathrm{Fe}(\mathrm{A})$ termination at the $\mathrm{Fe}_{3} \mathrm{O}_{4}(001)$ surface. Surf Sci 605:L42-L45

39. Davis EM, Zhang K, Cui Y, Kuhlenbeck H, Shaikhutdinov S, Freund H-J (2015) Growth of $\mathrm{Fe}_{3} \mathrm{O}_{4}(001)$ thin films on $\mathrm{Pt}(100)$ : tuning surface termination with an Fe buffer layer. Surf Sci 636:42-46

40. Spiridis N, Barbasz J, Łodziana Z, Korecki J (2006) $\mathrm{Fe}_{3} \mathrm{O}_{4}(001)$ films on $\mathrm{Fe}(001)$ : termination and reconstruction of iron-rich surfaces. Phys Rev B 74:155423

41. Mulakaluri N, Pentcheva R (2012) Hydrogen adsorption and siteselective reduction of the $\mathrm{Fe}_{3} \mathrm{O}_{4}(001)$ Surface: insights from first principles. J Phys Chem C 116:16447-16453 
42. Łodziana Z (2007) Surface Verwey transition in magnetite. Phys Rev Lett 99:206402

43. Pentcheva R, Moritz W, Rundgren J, Frank S, Schrupp D, Scheffler M (2008) A combined DFT/LEED-approach for complex oxide surface structure determination: $\mathrm{Fe}_{3} \mathrm{O}_{4}(001)$. Surf Sci 602:1299-1305

44. Henderson MA, Otero-Tapia SE, Castro M (1999) The chemistry of methanol on the $\mathrm{TiO}_{2}(110)$ surface: the influence of vacancies and coadsorbed species. Faraday Discuss 114:313-329
45. Feng T, Vohs JM (2004) A TPD study of the partial oxidation of methanol to formaldehyde on $\mathrm{CeO}_{2}$-supported vanadium oxide. J Catal 221:619-629 